\title{
O Nomear e a Ordem
}

[Naming and Order]

\author{
Fabien Schang*
}

Resumo: Inspirada pela distinção que, através do conceito auxiliar de necessidade, Kripke estabelece entre os conceitos de analiticidade e a aprioridade, a tese central do presente artigo é a de que há mais tipos de atitudes políticas do que se costuma admitir. A falta de algumas dessas atitudes no espectro político vem de uma confusão profunda entre os conceitos de direita e de conservadorismo. Além disso, a separação entre os tipos de ordem econômica e moral, justificará as atitudes mais originais de 'conservadorismo de esquerda' e de 'progressismo de direita' ao mesmo tempo que explicará as noções ambíguas de centros e extremos políticos. Em conclusão, uma comparação entre valores políticos e valores lógicos (verdade e falsidade), permitirá uma explicação das atitudes ambivalentes 'esquerda e direita' e 'nem esquerda nem direita', seja como casos de confusões conceituais, seja como um colapso do discurso político no 'extremo-centro'. Palavras-chave: Conservadorismo. Direita. Esquerda. Extremo-centro. Ordem.

\begin{abstract}
Inspired by Kripke's distinction between the concepts of analyticity and aprioricity though the auxiliary concept of necessity, the central thesis of the present paper is that there are more kinds of political attitudes than expected; the lack of some of these in the political spectrum comes from a deep confusion between the concepts of right and conservatism. Furthermore, the separation between two kinds of order -economical and moral, will justify the more original attitudes of 'left conservatism' and 'right progressivism' whilst accounting for the more ambiguous notions of political centers and extremes. Finally, a comparison between political values and logical values -truth and falsity, will allow an explanation of the ambivalent attitudes 'left and right at once' and 'neither left nor right' either as cases of conceptual confusions or as a collapse of the political discourse into 'extreme center'.
\end{abstract}

Keywords: Conservatism. Extreme Center. Left. Order. Right.

\footnotetext{
${ }^{*}$ Professor visitante do Departamento de Filosofia da Universidade Federal de Goiás (UFG). Doutor em Filosofia pela Université de Nancy 2/Lorraine (França). Realizou Pós-doutorado financiado pela Maison des Sciences de l'Homme/Franz Thyssen Stiftung na Technische Universität Dresden (Alemanha), bem como pós-doutorado na Higher School of Economics de Moscou (Rússia), e Pósdoutorado na Universidade Estadual de Maringá (UEM). Pesquisador visitante nas Universidades de Kolkata, Hyderabad, Mumbai e Chennai (India), financiado pela Indo-European Research Training Network in Logic (IERTNiL). E-mail: schangfabien@gmail.com. ORCID: https://orcid.org/0000-0003-3918-7629.
} 


\section{Introdução: Quando dizer não é fazer}

É mais fácil concordar com os homens sobre seu desejo de ir para o céu do que dar-lhes os meios para ir para lá. (André Malraux)

Durante meu primeiro curso de filosofia no ensino médio, minha professora (Sra. Martine Dumont) havia elaborado uma espécie de tipo ideal de filósofo com base em dois critérios principais de definição: aqueles que pensam ou não pensam algo, e aqueles que fazem ou não fazem algo. Surgiram três categorias principais de pessoas: (i) aqueles que fazem o que pensam (os 'coerentes'); (ii) aqueles que pensam no que fazem (os 'pragmáticos'); e, finalmente, (iii) a categoria daqueles que não fazem o que pensam. Poderíamos estender essa tipologia precisando que aqueles que fazem o que pensam não necessariamente pensam o que fazem, e viceversa (iv); ou que os melhores deles, os 'sábios', devem fazer o que pensam e pensar o que fazem do mesmo jeito $(v)$, o que inclui e excede o significado da primeira categoria. Também podemos conceber que algumas pessoas nunca fazem o que pensam (vi) ou nunca pensam o que fazem (vii), o que difere da terceira categoria, a dos inconstantes casuais.

A lista é, portanto, mais complexa do que parece, bem como as relações lógicas entre seus termos. De fato, essa lista poderia ser mais complicada se destacarmos a outra conexão sutil e ambí- gua entre dizer e pensar. E óbvio dizer que os homens nem sempre dizem o que pensam nem sempre pensam o que dizem, e isso por várias razões, como mentira ou ignorância. Se tomarmos o cuidado de distinguir dois significados do verbo 'pensar': pensar $_{1}$ como estar simplesmente ciente de algo, por um lado, ou pensar ${ }_{2}$ como aprovar algo, por outro lado, então é impossível dizer o que não pensamos ${ }_{1}$ quando é possível dizer o que não pensamos 2 . Vamos, portanto, eliminar o primeiro significado e limitar nossa atenção ao 'pensamento ${ }_{2}$ '. Esse significado pode ser cognitivo ou moral, dependendo de o pensamento ${ }_{2}$ expressar a crença de que uma proposição é verdadeira ou a convicção de que uma ação é boa. É o último significado do pensamento ${ }_{2}$ que nos interessará no que se segue, visto que o artigo é dedicado à ação política. Consequentemente, outra tipologia de comportamento aparece, substituindo 'pensar' por 'dizer': existem aqueles que sempre dizem o que fazem ( $i$ ') e aqueles que sempre fazem o que dizem (ii'), aqueles que às vezes não dizem o que fazem (iii') ou às vezes não fazem o que dizem (iv'), aqueles que sempre fazem o que dizem e sempre dizem o que fazem $\left(v^{\prime}\right)$, então aqueles que nunca fazem o que dizem $\left(v i^{\prime}\right)$ e que nunca dizem o que fazem (vii').

A complexidade do significado das expressões acima pode, portanto, ser acentuada, se dividirmos o conceito inicial de pensamento em conceitos auxi- 
liares de pensamento explícito (dizer o que pensamos) e pensamento implícito (não dizer o que o pensamos). Várias questões subjacentes à atividade política estão relacionadas a essas duas classificações logicamente vinculadas. A crise atual na representação política se deve ao fato de os políticos não fazerem o que dizem, ou não fazem o que pensam? Tal questão não é nem meramente retórica nem irrelevante para o nosso propósito. Por um lado, a distinção entre pensar e dizer fica no centro da atividade política, ao menos nos estados democráticos onde a autoridade depende de um contrato de confiança entre governados e governantes. No entanto, qualquer discordância entre o discurso oficial e a ação executiva produz um conflito entre dizer e fazer. Nesse caso, a distinção semântica entre pensar e dizer leva à distinção política entre mentira e paternalismo - quem não faz o que diz mente, enquanto quem não faz o que pensa sem dizer pode esconder algum tópico difuso para o seu eleitorado. A crise política atual depende em grande parte disso, isto é, a dificuldade para distinguir o que os políticos pensam abertamente e o que eles deixam difuso nos discursos oficiais. Por outro lado, verifica-se que essa distinção é análoga a uma discussão extremamente relevante na estruturação do discurso filosófico sobre as modalidades. Assim, a separação realizada por Kripke entre o conceito metafísico de necessidade e o epistêmico de contingência permi- tiu uma revisão profunda no discurso modal. Do mesmo modo, pretendemos que a distinção acima entre pensar e dizer funciona de uma maneira semelhante enquanto antecipa uma revisão igualmente profunda na estruturação do discurso político.

Outras questões relacionadas podem assim enriquecer o debate: os políticos profissionais fazem o que pensam, pensam o que dizem, ou dizem o que pensam? Em outras palavras, eles são acusados, acima de tudo, de serem mentirosos quando não dizem o que pensam, ou de serem incompetentes quando não fazem o que pensam? Para tentar obter uma imagem mais clara desses tipos de acusações, tentaremos avaliar o discurso político para revelar crenças e ações políticas. Isso pressupõe a existência de um critério para determinar o que os políticos devem dizer e fazer de acordo com os seus comprometimentos públicos: é precisamente a distinção entre esquerda e direita, que constitui o cerne deste artigo e cujo significado deve ser esclarecido a fim de desvelar a crise da representação política em relação a esses comprometimentos. Uma explicação mais precisa desses termos também poderia explicar outras noções ambíguas tais como a 'demagogia' (vi') e o 'paternalismo' (vii'). 


\section{1. 'Esquerda'? 'Direita'?}

Quando me perguntam se a distinção entre os partidos à direita e os partidos à esquerda, os homens à direita e os homens à esquerda, ainda faz sentido, a primeira ideia que me ocorre é que o homem que faz essa pergunta certamente não é um homem à esquerda. (Emile-Auguste Chartier, pseudônimo Alain)

A distinção política entre esquerda e direita gera algumas divergências fundamentais. Para um autor como Alain de Benoist (2017), fundador da Nova Direita, essa distinção não faz mais sentido e deve ser substituída por uma nova divisão entre populismo e elitismo. No entanto, se outros, como Chantal Mouffe (2018), tiverem razão ao proporem a manutenção da distinção entre populismo 'de esquerda' e populismo 'de direita', a nova clivagem proposto por De Benoist apenas adiciona precisão à clivagem persistente tradicional. Contrário ao abando da distinção entre esses dois campos, o cientista político Norberto Bobbio, que se considerou de centro-esquerda, entende a separação como uma ferramenta essencial para a análise da atividade política (1994).

Quem aqui tem razão e por que essa oposição fundamental entre dois pólos opostos deveria ser abandonada ou mantida? Uma explicação em três etapas pode ser apresentada para pensar que a oposição esquerda-direita não faz mais sentido. Primeiramente, a oposição tradicional entre os sistemas econômicos do capitalismo e do socialismo expirou desde o final da Guerra Fria e o desaparacimento do bloco oriental. Em segundo lugar, a multiplicação de novos temas políticos (ambientalismo, feminismo, soberanismo, antiespecismo, etc.) esvazia substancialmente a oposição binária inicial entre dois campos políticos. Por fim, o campo de reflexão política resultante dessa profusão de novas ideias é complexo demais para ser reduzido a essa oposição binária. Por exemplo, o ambientalismo pode ser combinado com posições ideologicas antagonistas tais como um anticapitalismo não-desenvolvimentista ou um 'capitalismo verde' sustentável; o feminismo pode ser combinado também com uma laicidade universal ou um comunitarismo indigenista. Falase, nos países europeus, de 'conspiração vermelho-marrom' para designar o conluio entre o comunismo da extremaesquerda e o nacionalismo da extremadireita, ou também o conluio entre o anti-sionismo da extrema-esquerda e o anti-semitismo da extrema-direita. Fala-se também de um perigo 'islamofascista' ou 'fascismo verde' nos países ocidentais, para enfatizar a incompa-

\footnotetext{
${ }^{1}$ A relevância da designação 'islamo-fascismo' como sinônimo de 'islamo-esquerdismo' foi criticada como fazendo combinações de ideologicas sem raízes históricas comuns e dissimulando na verdade um discurso islamofóbico de extrema-direita. Sobre essa es-
} 
tibilidade entre a religião mulçumana e os regimes democráticos. ${ }^{1}$ Assim, o campo político atual parece complicado demais para ser reduzido meramente a uma díade com polos excludentes.

Diante dessa confusão geral involuntária ou mal intencionada (e neste último caso se pode falar em 'confusionismo'), proporesmo a defesa da manutenção da distinção esqueda-direita por duas razões principais. A primeira é que a multiplicação de novos tópicos políticos não impede a manutenção da organização geral do discurso político em dois campos excludentes reciprocamente e autônomos. A segunda é que tal divisão não tem que ser associada a qualquer ideologia em particular, na medida em que ela transcende as épocas e os lugares onde ela se manifesta. Embora a clivagem esquerda-direita venha do contexto histórico particular da Revolução Francesa e tenha sido baseada inicialmente em um critério único, pró ou contra o absolutismo real, ela não depende disso e pode ser mantida como princípio organizador do pensamento político. No entanto, uma questão central permanece para justificar esse princípio: por que precisamente este, e não um outro princípio qualquer?

Para responder a essa pergunta, eliminaremos imediatamente alguns impasses. Entre eles, se encontra a ideia de que os partidários do abandono da divisão esquerda-direita pertenceriam à sensibilidade da 'extrema-direita', enquanto os partidários de sua continuação seriam fiéis aos princípios da democracia de opinião. Podemos descartar esse raciocínio por pelo menos duas razões: essa afirmação repousa na ideia de que uma análise metapolítica sempre depende de preferências tendenciosas e subjetivas; ao mesmo tempo, ela pressupõe que a extrema-direita é inimiga da democracia, estabelecendo uma conotação negativa ao debate antes mesmo que ele comece. Em vez de condenar antecipadamente os partidários da 'nem esquerda nem direita', proporemos uma análise o mais imparcial possível e baseada na analogia com uma área de reflexão que não tem nada político: a teoria dos juízos de Kant (2015), e sua modificação conceitual proposta por Saul Kripke (2012).

\section{Conceitos e significados}

Mudar o nome das coisas é aumentar a desgraça do mundo. (Albert Camus)

A análise conceitual a seguir visa explicar o significado dos conceitos de esquerda e direita, considerando que constituem opostos semânticos que funcionam, sobretudo, como pontos de re-

tratégia explicativa da chamada 'reductio ad hitlerum', veja a abordagem moralista do discurso político em (SCHANG. Politicamente falando: Um ensaio em filosofia da linguagem política). Para uma genealogia do conceito político de islamismo, veja (KRIPKE, 2012). 
ferência ou pontos cardeais cuja tarefa é orientar e, assim, dar sentido a qualquer discurso político. Esta análise é baseada em três premissas metodológicas que se sustentam mutuamente. A primeira é uma abordagem analítica da filosofia política ou, melhor ainda, um ensaio de politica formal, em oposição a uma abordagem histórica e sob a qual o significado dos conceitos políticos depende das condições de verdade das sentenças em que eles ocorrem. A segunda é uma analogia estrutural entre diferentes famílias conceituais, que identifica estruturas lógicas comuns entre diferentes grupos de conceitos mutuamente independentes. A terceira é uma definição prescritiva e não descritiva desses conceitos. Certamente, nada impede de listar os diferentes partidos políticos da esquerda e da direita, de acordo com os tempos e os países em que esses conceitos adquiriram um uso comum. Para nossa análise, negaremos o valor explicativo dessa abordagem descritiva, porque ela enfatiza excessivamente nas diferenças caso a caso e perde de vista as características essenciais desses conceitos.

Uma objeção óbvia contra essa abordagem prescritiva é que nenhuma explicação pode ser válida sem incluir exemplos reais de quaisquer movimentos ou partidos associados à esquerda ou à direita na história do pensamento político. De fato, a que serviria impor uma definição se esta não leva em conta a complexidade dos usos reais dos conceitos ? Nossa resposta é que tal objeção coloca a carroça na frente dos bois ao mal compreender o papel dos modelos teóricos: é o uso real de um conceito que deve ser baseado em sua definição essencial, e não vice-versa. A palavra 'essencial' pode ser enganosa, no entanto, e é preciso evitar cair em um essencialismo ingênuo pelo qual os conceitos de esquerda e direita teriam condições necessárias e suficientes para serem definidas. Trate-se de examinar se tais conceitos se comportam como termos de espécies naturais submetidos à algumas necessidas taxonômicas, ou se o significado é um produto aleatório das contingências históricas. Kant e Kripke são dois autores que pensam a noção de necessidade e os exemplos aos quais eles recorrem vão inspirar o problema do significado dos conceitos políticos. Neste sentido, dizer que a direita é conservadora e que a esquerda é progressista, seria tão verdadeiro quanto a afirmação de que o ouro é amarelo, para Kant (2015), e de que e a água é $\mathrm{H}_{2} \mathrm{O}$, como par Kripke (2012), isto é, equivaleria a uma necessidade?

Para justificar essa abordagem analítica e prescritiva do discurso político diremos, para simplificar, que uma explicação apropriada dos conceitos políticos de esquerda e direita repousa, acima de tudo, sobre a distinção entre

${ }^{2}$ Veja Hintikka (1968), onde o autor justifica o projeto de um lógica do conceito de conhecimento contra argumentos de filósofos da 
o significado básico de um conceito e seu significado residual. ${ }^{2} \mathrm{O}$ significado 'básico' de um conceito é o conjunto de propriedades que ele deve ter para expressar um significado padronizado e, assim, relevar uma certa 'lógica de profundidade'; os significados residuais, por outro lado, são todos os usos que esse conceito pode receber na linguagem comum e que não correspondem ao seu uso básico. Por certo, a distinção entre esses dois tipos de uso não pode ser justificada sem admitir um papel essencial dos conceitos estudados. Isso não significa, no entanto, que a expressão do significado básico repouse inteiramente em uma postulação ou convenção arbitrária, contra todos seus significados residuais. Pelo contrário, isso significa que o conceito em consideração segue uma função geral. O conceito de díade (BOBBIO, 1994) é particularmente adequado para caracterizar a função essencial dos conceitos de esquerda ou direita no discurso politico, que é a de expressar uma oposição ou desacordo fundamental, sem o que a atividade política não tem sentido. Explicar as fontes dessa 'lógica subjacente' é o objetivo principal deste artigo, além das muitas variações semânticas que os dois conceitos de esquerda e direita podem ter encontrado no passado e ainda encontrarão no futuro. O resultado dessas variações é um conjunto complexo de conceitos interconectados, cuja complexidade manifesta a vida das ideias políticas através da história mas não impede a necessidade de esclarecer essas relações até o significado básico dos conceitos.

De acordo com a metodologia apresentada na introdução, um problema filosófico pode ser resolvido a partir de uma análise das relações lógicas entre seus conceitos. Para destacar nossa análise conceitual das condições de verdade de agora em diante recorremos ao simbolismo da lógica da primeira ordem. Isso inclui as constantes proposicionais do condicional $\rightarrow$, do bicondicional $\leftrightarrow$, da conjunção $\wedge$, e da negação $\neg$. Com isto, sejam $S, P$ e $Q$ quaisquer conceitos, $Q$ sendo a negação de $P$. Então:

- ' $S \rightarrow P$ ' significará 'Algo é $S$ somente se ele é $P$ ', ou 'Algo não pode ser $S$ sem ser $P^{\prime}$.

- ' $S \leftrightarrow P$ ' significará 'Algo é $S$ se e somente se ele é $P$ ', ou 'Algo não pode ser $S$ sem ser $P$, e reciprocamente'.

- ' $S \wedge Q$ ' significará 'Algo é $S$ e $Q$ ', ou 'S não implica P'.

- ' $\neg(S \rightarrow P)$ ' ou ' $(S \wedge \neg P)$ ' significará 'Nem todo $S$ é P', isto é, 'Algo é $S$ e não é $P$ '.

O seguinte caso irá ilustrar como es- 
sas relações lógicas ocorrem no centro dos debates filosóficos.

Segundo Kant, qualquer juízo declarativo do tipo ' $S$ é $P$ ' pode ser caracterizado por dois pares de propriedades contraditórias: (1) analítico ou (2) sintético, dependendo de o predicado $P$ estar contido ou não na definição do sujeito $S$; (3) a priori ou (4) a posteriori, dependendo de a atribuição da propriedade $P$ ao termo sujeito $S$ ser independente ou depende da experiência. Uma combinatória abstrata, portanto, leva a quatro tipos de juízo concebíveis:

- analíticos a priori: $(\alpha)=(1) \wedge(3)$

- analíticos a posteriori: $(\beta)=(1) \wedge($

- sintéticos a priori: $(\gamma)=(2) \wedge(3)$

- sintéticos a posteriori: $(\delta)=(2) \wedge$

Kant é famoso por ter defendido que, contra a tradição filosófica anterior, $(\gamma)$ é concebível. Ele também afirmou que $(\beta)$ é inconcebível, uma vez que a analiticidade excluiria imediatamente qualquer uso da experiência.

A posição de Kant na lista dos possíveis tipos de juízo não foi unanimemente aceita pela comunidade filosófica. Positivistas lógicos como Carnap excluíram não apenas $(\beta)$ mas também $(\delta)$, enquanto Quine (1975) desafiava a própria legitimidade da distinção analítico-sintético e, portanto, desafiava a relevância filosófica dos quatro tipos de juízo $(\alpha)-(\delta)$. Mas a posição mais original sobre esse assunto, sem dúvida, vem de Kripke (2012). Aparentemente, Kripke aceita os quatro tipos de juízo sem excluir nenhum deles. Mas, em uma inspeção mais minuciosa, ele o faz modificando um pouco os termos do debate inicial estabelecendo uma distinção semelhante àquela da introdução entre pensar e dizer. Partindo da definição adicional em virtude da qual um juízo analítico (1) é necessário (5) e (3) a priori: $(1)=(5) \leftrightarrow(3)$, Kripke enriquece o debate ao introduzir um conceito filosófico adicional: o da necessidade (5), e seu contraditório da contingência (6). É em torno deste último que Kripke defenderá uma posição sem precedentes. Visto que, de Kant a Quine, todos os filósofos consideram que um juízo é necessário se e somente se as respectivas negações da contingência e da aposterioridade também seriam equivalents, (6) $\leftrightarrow$ (4), Kripke, pelo contrário, afirma que os conceitos de necessidade e aprioridade são logicamente independentes. De acordo com sua argumentação, existem proposições necessárias a posteriori, (5) $\wedge(4)$, na medida em que necessidade não implica aprioridade, assim como há proposições contingentes $a$ priori $(6) \wedge(3)$, na medida em que aprioridade não implica necessidade. Essa posição iconoclasta é inteiramente baseada na definição de necessidade, que Kripke concebe como segue: uma proposição é necessária se e somente se for verdadeira em todos os mundos possíveis. Consequentemente, a existência 
de proposições necessárias a posteriori significa que existem proposições verdadeiras em todos os mundos possíveis e cuja atribuição de verdade repousa em uma confirmação experimental; o exemplo de uma proposição necessária a posteriori dada por Kripke é 'Água é $\mathrm{H}_{2} \mathrm{O}^{\prime}$. E a existência de proposições contingentes a priori significa que certas proposições cuja atribuição da verdade é independente da experiência não são verdadeiras em todos os mundos possíveis. O exemplo de uma proposição contingente a priori dado por Kripke é 'O metro-padrão de Paris tem um metro de comprimento'. Apesar dos escrúpulos do lógico Quine na introdução de 'mundos possíveis' neste debate, faria sentido falar de proposições necessárias a posteriori ou proposições contingentes a priori. E a razão pela qual essas combinações de propriedades parecem inconcebíveis é, sem dúvida, devido à equivalência lógica tradicionalmente aceita entre necessidade e aprioridade, tornando $(\beta)$ um sinônimo dos juízos necessários a posteriori. Ao dissociar necessidade e aprioridade, Kripke mostra, pelo contrário, que é possível admitir juízos necessários a posteriori sem admitir que juízos analíticos a posteriori sejam concebíveis. De fato, Kripke segue Kant e a tradição na rejeição de $(\beta)$, mas ele abre o debate insistindo no conceito de necessidade.

O mesmo processo de dissociação conceitual também foi aplicado ao caso da teoria dos desejos de Epicuro
(SCHANG, 2016) A situação teórica é semelhante à da teoria dos juízos de Kant, apesar de seu conteúdo muito diferente. Segundo Epicuro, todo desejo pode ser caracterizado novamente por dois pares de propriedades contraditórias: aqueles que são necessários (5) e aqueles que não são, ou seja, os que são contingentes (6); aqueles que são naturais (7) e aqueles que não são, que qualificaremos como culturais (8). Uma combinação desses conceitos fornece quatro tipos de desejos, novamente:

- necessários naturais: $\left(\alpha^{\prime}\right)=(5) \wedge(7)$

- necessários culturais: $\left(\beta^{\prime}\right)=(5) \wedge(8)$

- contingentes naturais: $\left(\gamma^{\prime}\right)=(6) \wedge(7)$

- contingentes culturais: $\left(\delta^{\prime}\right)=(6) \wedge(8)$

Como se vê, a classificação epicurista dos tipos de desejos corresponde exatamente à classificação kantiana dos tipos de juízo, com base nas relações análogas (1)-(5), (2)-(6), (3)-(7) e (4)-(8): a tradição kantiana recusa a existência dos juízos analíticos a posteriori: $\neg((1)$ $\wedge(4))$, assim como a tradição epicurista recusa a existência dos desejos necessários e culturais: $\neg((5) \wedge(8))$. Isso leva a uma conclusão logicamente idêntica. No primeiro caso, todos os juízos analíticos são a priori e existem juízos a priori que não são analíticos: $(1) \rightarrow(3)$, assim como, no segundo caso, todo desejo necessário é natural e há desejos naturais que não são necessários: $(5) \rightarrow(7)$. Mas, assim como Kripke contestou a relação 
de implicação entre necessidade e aprioridade, afirmando que analiticidade e necessidade não são equivalentes, o autor afirma que também há razões para contestar a relação de implicação entre necessidade e naturalidade (SCHANG, 2016). Se for esse o caso, existem desejos culturais e necessários: $(5) \wedge(8)$, assim como deve haver juízos necessários e a posteriori. Não entraremos nos detalhes desse argumento, enfatizaremos apenas a analogia estrutural dos dois tipos de raciocínio relacionados às teorias do juízo e do desejo. E, acima de tudo, essa hipótese não epicurista de desejos necessários e culturais ao mesmo tempo parece proceder da mesma maneira que as declarações necessárias a posteriori de Kripke, deslocando o sentido cosmológico de necessidade para um sentido antropológico de necessitação.

Agora, uma questão poderia ser formulada contra esse processo comum, tanto em relação a necessidade de Kripke quanto a necessitação: a necessidade teria o mesmo significado para Kripke e Kant, mesmo considerando que a noção de definição de 'mundo possível' nunca aparece na formulação kantiana da teoria da razão teórica? De fato, o argumento de Kripke introduz no debate kantiano a necessidade de tipo metafísico compatível com a fonte empírica de seu conhecimento e, portanto, distingue-se da necessidade lógica de proposições verdadeiras por definição ou tautologias. Na mesma linha, a noção anterior de necessidade intro- duziu no debate epicurista uma necessidade de tipo antropológico, compatível com a fonte cultural de sua produção e, portanto, distingue-se da necessidade de tipo natural. Essa distinção entre duas interpretações de um conceito dado será repetida abaixo, no caso das categorias políticas. Vamos mais longe, porém, nessa 'crítica à crítica' da tipologia dos juízos de Kant: mudando o significado dos conceitos, como no caso do conceito auxiliar de necessidade, não se está mudando de assunto (plagiando Quine, 1986) e, assim, criando um problema filosófico falso a partir de uma confusão conceitual? A referência feita à Quine será útil mais adiante, considerando que a preocupação de Quine esteja relacionada apenas às condições de verdade e falsidade dos conectores lógicos. No futuro caso dos conceitos políticos, a questão também se relacionará com a busca de condições significativas para categorias políticas tais como esquerda e direita.

Antes de focar nessa relação entre valores lógicos (verdadeiro-falso) e valores políticos (esquerda-direita), vamos ao cerne do assunto: a classificação dos tipos de comportamento político.

\section{Os dois dogmas da ciência política (a distinção esquerda-direita e o pro- gressismo)}

Como nas famílias conceituais dos juízos kantianos e dos desejos epicuristas, 
dois pares de propriedades contraditórias tornam possível caracterizar o comportamento político: aqueles que são de direita (9) e aqueles que não são (10); aqueles que são conservadores (11) e aqueles que não são (12). Será acordado que todos aqueles que não estão à direita estão automaticamente 'à esquerda', embora haja algumas razões para contestar essa implicação lógica, o que analisaremos mais adiante. Assim como aqueles que não são conservadores sejam comumente referidos como 'progressistas', mas empregaremos esse qualificador com cautela para não introduzir conotações positivas ou negativas infundadas. Bobbio (1994) considera esses juízos de valor subjetivos como inevitáveis no campo do discurso político, mas devem ser evitados o máximo possível para manter uma análise conceitual o mais imparcial possível. Assim, chegamos novamente a uma lista combinatória de quatro possíveis atitudes políticas:

- direita conservadora: $\left(\alpha^{\prime \prime}\right)=(9) \wedge(11)$

- direita progressista: $\left(\beta^{\prime \prime}\right)=(9) \wedge(12)$

- esquerda conservadora: $\left(\gamma^{\prime \prime}\right)=(10) \wedge(11)$

- esquerda progressista: $\left(\delta^{\prime \prime}\right)=(10) \wedge(12)$

Deve-se notar, no entanto, que o discurso político parece mais complexo que as famílias conceituais anteriores, na medida em que inclui nuances terminológicas adicionais, como as noções de 'centro' e 'extremo'. Há um sentido em falar de atitudes de 'centroesquerda' ou 'centro-direita' e 'extrema- esquerda' ou 'extrema-direita', embora seja difícil perceber o que poderia significar um juízo 'semi-analítico' ou um desejo 'ultra-necessário'. Voltaremos a essas noções adicionais, dando-lhes um significado compatível com a classificação de atitudes políticas anunciadas acima. Entretanto, verifica-se que a opinião comum dos cientistas políticos sobre atitudes políticas (supondo que alguma seja reconhecida nessa comunidade de analistas) é semelhante à opinião da epistemologia dos empiristas pré-kantianos e dos empiristas lógicos. Assim como estes últimos consideram logicamente equivalentes os juízos analíticos e a priori, (1) $\leftrightarrow(3)$, o que também se aplica a seus respectivos opostos, que são os juízos sintéticos e a posteriori, (2) $\leftrightarrow$ (4), os primeiros parecem assimilar o conservadorismo à direita $(9) \leftrightarrow(11)$ e o progressismo à esquerda $(10) \leftrightarrow(12)$. Isso equivale logicamente a pensar que não há esquerda conservadora, $\neg((9) \wedge(12))$ tanto quanto não há direita progressista, $\neg((10) \wedge(11))$.

Mas antes de refutar essa opinião amplamente compartilhada, ainda é necessário concordar com as expressões que a compõem. Devemos, portanto, propor uma definição inicial para os conceitos de direita e conservadorismo, antes de considerar seus opostos contraditórios de esquerda e progressismo.

Como o nome sugere, o 'conservadorismo' pode ser caracterizado como a atitude de quem quer manter algo, ou não mudá-lo. A grande dificul- 
dade, muitas vezes deixada despercebida, vem da identidade do que deve ser preservado e de como preservá-lo. Embora possa parecer paradoxal reivindicar preservar o que não é mais (depois de ter sido) no caso dos 'reacionários', podemos falar de um certo conservadorismo cujo objetivo seria restaurar uma ordem das coisas da tradição ou ordem das coisas naturais. Quanto à identidade do que deve ser preservado, pode ser tanto uma ordem moral quanto um tipo de governo decaído ou o ambiente natural. Para simplificar a noção sem disfarçá-la, qualificaremos como conservadorismo a atitude política de quem faz do grupo a medida de todas as normas políticas e privilegia as instituições coletivas (família, Estado, religião) sobre as vontades particulares ou, em outras palavras, a coexistência sobre a existência. Como resultado, entendemos por 'progressismo' a atitude oposta daqueles que tornam o indivíduo a medida de todas as normas políticas e favorecem as vontades individuais sobre as instituições coletivas, ou seja, a existência de cada um sobre convivência com os outros. Isso ajuda a vincular progressismo e iluminismo, considerando que nenhuma decisão superior pode ser tomada legitimamente sem a avaliação concordante das razões de sujeitos particulares. Surge, portanto, a seguinte questão: até que ponto o conservadorismo deveria ser de direita?

Com relação a esse conceito de 'direita', não se pode mais contar as vá- rias tentativas de definir seu significado e o de seu oposto, que é a 'esquerda'. Em vez de uma análise descritiva e histórica comparável as de René Rémond (1954) (para a direita) e Jacques Julliard (2012) (para a esquerda), tentemos caracterizar a linha por uma propriedade comum. Uma hipótese plausível seria a preocupação com a ordem das coisas. Essa ordem pode ser de origem humana ou não (divina ou simplesmente natural), pois pode se referir à ordem estabelecida ou à de outra época. A esquerda seria, portanto, a negação desses diferentes significados do conceito de ordem, e seu significado variará ainda mais, dependendo do significado atribuído ao conceito de ordem. Mas se virarmos o problema de cabeça para baixo e começarmos a análise definindo a 'esquerda' como a preocupação com a igualdade, segue-se que a direita se torna sinônimo de desigualdade. Contudo, assim como não queremos associar a esquerda à expressão pejorativa de desordem e preferimos a idéia de rejeição do autoritarismo a ela, também não associaremos a direita à conotação pejorativa de desigualdade e preferiremos a idéia de rejeição do igualitarismo quando falando da direita.

Outra maneira comum (e igualmente equívoca) de caracterizar direita e esquerda é a seguinte : a direita afirmaria que a liberdade é um valor político que prevalece sobre o da igualdade, enquanto a esquerda afirmaria que é o valor de igualdade que prevalece sobre o 
da liberdade. ${ }^{3}$ Aqui chegamos ao cerne da dificuldade em nossa análise conceitual. O conceito de liberdade é tão vago na filosofia da política e da moralidade quanto o conceito de necessidade na filosofia metafísica e na epistemologia, pois é a partir daí que parecem surgir as divergências relacionadas à existência de diferentes juízos e diferentes atitudes políticas. Além disso, a busca por harmonia social parece unânime na política e produz controvérsias apenas se a chamada 'ordem' implica um autoritarismo arbitrário. Portanto, não podemos reter a ordem simples como critério característico da direita, pois esse conceito funciona muito mais como um ideal político comparável ao da verdade na teoria do conhecimento. E, assim como analítico e sintético são dois modos de verdade, são as modalidades dessa ordem ou harmonia social que se trata de revelar a fim de distinguir a direita da esquerda.

Chegamos agora ao ponto principal da nossa argumentação. Neste ponto pretendemos apresentar nossa contribuição particular para um ensaio em filosofia política analítica - como uma norma geral que ajude a delimitar o domínio do discurso político em vez de uma descrição histórica das numerosas correntes políticas de acordo com os tempos e lugares. Partamos, assim, da afirmação de que a modalidade da direita para garantir harmonia social é a manutenção da ordem estabelecida, enquanto a modalidade da esquerda repousa, ao contrário, na alteração dessa ordem estabelecida. Podemos, portanto, entender porque o conservadorismo parece andar de mãos dadas com a atitude da direita, se esta favorece instituições às quais o conservador se submete em princípio. É certo que o significado de 'ordem' fica um tanto ambíguo, mas procuraremos esclarecê-lo no que segue. Dar uma análise mais detalhada desse conceito de ordem será o objetivo central do fim desta seção, considerando que a relevância dele é tão grande no domínio do discurso político quanto a do conceito de necessidade no domínio do discurso metafísico.

Alguns esclarecimentos ainda devem ser feitos sobre vários conceitos anexos a (9)-(12), a fim de justificar nossa caracterização acima. Por um lado, devemos nos pergunta se é oportuno opor a liberdade à igualdade. Bobbio insiste que esses dois valores políticos não são mutuamente excludentes, mas relativamente complementares: é possível defender os dois valores de uma só vez, mas em proporções misteriosas que ainda precisam ser determinadas com base em várias tendências comportamentais. Isso significa, antes de tudo, que liberdade e igualdade não são

\footnotetext{
${ }^{3}$ Um exemplo de análise onde a igualdade ocorre como propriedade essencial da esquerda é o de Salanskis (2009). O seguinte quer mostrar que o conceito de igualdade deriva de outros mais centrais e não é tão relevante para o esclarecimento da oposição esquerda-direita.
} 
conceitos contraditórios, como os casos analíticos/sintéticos, a priori/a posteriori, etc. Por outro lado, será correto afirmar que a liberdade implica a negação da ordem? Ou ainda: a doutrina do anarquismo é uma promoção da desordem (mas uma rejeição da ordem injusta)? Como se vê, o problema novamente reside na confusão ou falta de clareza dos conceitos estudados na filosofia política. Tal situação lembra furiosamente a atitude de Quine em relação à distinção entre analítico e sintético, e usaremos essa analogia para justificar nossa classificação exaustiva de atitudes políticas e a idéia de uma distinção de grau (e não de natureza) entre esquerda e direita.

Mas antes disso, observamos a ocorrência na sentença anterior, usada para distinguir anarquismo e desordem simples, de um novo termo anexo: justiça. No entanto, esse novo termo é tão positivo e vagamente conotado quanto o da liberdade, dependendo se ele é baseado em uma norma natural ou social. $\mathrm{O}$ que fazer com esses termos, se eles deveriam esclarecer a situação conceitual enquanto produzem ainda mais confusão ? A resposta é a seguinte: entender seu uso no campo lexical da política por analogia ao campo lexical da epistemologia. Sendo a justificação o que é apropriado para levar à verdade, a justiça refere-se, portanto, ao modo de realização do bem e participa da oposição entre conservadorismo e progressismo. Esse também é o estatuto do ideal em relação à realidade, e a ordem das coisas (que deve ser o caso) em relação ao estado das coisas (o que é o caso). Aqui vemos o enorme mal-entendido produzido pelo conceito de ordem, dependendo se é entendida como a ordem atual estabelecida pelo direito positivo ou uma possível ordem estabelecida pelo direito natural. Como consequência, a outra noção anexa de liberdade se opõe ou não ao conceito de ordem de acordo com o que cada um significa: liberdade não se opõe à ordem, se esta é justificada por regras morais e se significa um ideal de emancipação em relação às ordens coletivas injustas. Mas essa noção de liberdade é tão confusa quanto inútil para nosso propósito: ninguém promove a ignorância ou a total falta de conhecimento, assim como não queremos injustiça ou total falta de liberdade para nós mesmos. Por esse motivo, temos o direito de substituir o conceito tendencioso de liberdade pelo conceito mais neutro de emancipação. É, portanto, o último que servirá a partir de agora para esclarecer as diferentes atitudes políticas. Em outras palavras, a liberdade se opõe à ordem apenas no seu sentido mais trivial de livre arbítrio ou falta de conduta regulada (em referência ao que Descartes chamou de 'mais baixo grau de liberdade'). Ela é um ideal orientador comparável à verdade, enquanto sua compreensão mais estreita do conceito de emancipação indica um meio de atingir esse ideal político. 
Em resumo, todas as famílias conceituais consideradas até agora sempre se baseiam em dois tipos de conceitos emparelhados $(\mathrm{X})-(\mathrm{Y})$ : os primeiros $(\mathrm{X})$ são tipos de ideais a serem alcançados (analiticidade, necessidade, direita), seja a verdade para os juízos kantianos, a felicidade para os desejos ou o bem comum para as atitudes políticas; enquanto os segundos (Y) são meios de atingir esses valores orientadores (aprioricidade, naturalidade, conservadorismo).

\begin{tabular}{|c|c|c|c|c|c|}
\hline Conceitos & $\mathbf{X}_{1}$ & $\mathbf{X}_{2}$ & $\mathbf{Y}_{1}$ & $\mathbf{Y}_{2}$ & auxiliários \\
\hline ser & pensar & não pensar & fazer & não fazer & dizer \\
\hline juízo & analítica & sintético & a priori & a posteriori & necessário \\
\hline desejo & necessário & contingente & natural & cultural & necessitação \\
\hline política & direita & esquerda & conservador & progressisto & ordem \\
\hline
\end{tabular}

O conservadorismo se refere à idéia de preservar um estado de coisas comum, mas resta saber se este é atual ou não para poder identificar os diferentes tipos de conservadores. A direita referese à noção de ordem das coisas estabelecidas, mas resta saber de qual tipo de ordem se trata para poder distinguir os diferentes tipos de direita.

O que emerge dessa análise é que prevalece a confusão entre as noções de conservadorismo e direita. Essa confusão é análoga àquela entre juízos $a$ priori e juízos necessários. Como lembrete, Kant 'quebrou' o átomo aparente do analítico a priori em seus dois elementos distintos antes de Kripke isolar a molécula da analiticidade do átomo de necessidade, esta sendo um constituinte essencial dela combinada com aprioridade. Foi, portanto, o conceito auxiliar de necessidade metafísica que permitiu a Kripke justificar novas formas de juízo, como juízos necessários a priori e necessários a posteriori, en- tão juízos contingentes a priori e contingentes a posteriori. Da mesma forma, é provável que o átomo aparente da direita conservadora possa ser dividido em seus dois elementos distintos. Resta revelar o conceito auxiliar que provavelmente isolará a molécula da direita da qual seria também um átomo constituinte: será a ordem estabelecida de 'o que é o caso', mas dividida entre um sentido econômico e um sentido moral. Por analogia com a distinção estabelecida por Kripke entre necessidade metafísica e necessidade lógica, também é possível distinguir dois tipos de ordem política: uma ordem econômica, que se refere à norma dos modos de produção e troca de bens materiais entre os membros de uma determinada comunidade e uma ordem moral, que se refere às normas comportamentais dos indivíduos no espaço público. Assim como não há relação de dependência particular entre necessidade metafísica e necessidade lógica, a ordem econômica é 
independente da ordem moral.

Voltemos agora ao que parecia ser a taxonomia usual de atitudes políticas, taxonomia limitada a uma oposição binária entre a direita conservadora e a esquerda progressista. Se a expressão 'direita progressista' pode incomodar o senso comum, é na medida em que o progressismo emancipatório é assimilado ao protesto da esquerda contra a ordem estabelecida; assim como a expressão 'esquerda conservadora' enfrenta um obstáculo epistemológico, desde que associemos o conservadorismo ao respeito da direita pela ordem estabelecida. O conceito de 'liberal-libertário' introduzido por Michel Clouscard (2008) parece, no entanto, uma expressão bastante indicada para o primeiro: o lado libertário se refere ao progressismo emancipatório dos indivíduos, enquanto o lado liberal corresponde à atual ordem econômica capitalista, assim produzindo uma síntese entre cidadão e consumidor que é específica ao progressismo de direita. Movimentos como o sindicalismo revolucionário de Georges Sorel ou o nacionalbolchevismo de Ernst Niekisch também parecem ilustrações do conservadorismo de esquerda, uma vez que sua vontade de defender órgãos sociais como a família ou a classe trabalhadora se combina com a necessidade de derrubar as instituições políticas capitalistas existentes. ${ }^{4}$ Nesse sentido, 'manter' não significa manter a ordem dominante, mas, pelo contrário, estabelecer uma ordem econômica alternativa. Outro caso concebível de conservadorismo de esquerda é o anarquismo de Proudhon, que Isabel (2017) descreve como um programa de defesa da classe trabalhadora em nome de valores morais tradicionais, tais como família e trabalho. Estamos longe da imagem usual do anarquismo, e isso pode parecer uma razão suficiente para recusar esse viés da esquerda. Uma objeção contra a existência de tal 'conservadorismo de esquerda' é que Proudhon, Sorel e Niekisch compartiham opiniões anti-semitas que são explicitamente incompatíveis com o universalismo histórico da esquerda herdada da Revolução Francesa e, também, inspiraram os movimentos fascistas dos anos $1920 .^{5}$ Nesse caso, quem é anti-semita (14) não poderia ser de esquerda, de tal modo que o antissemitismo seria uma condição suficiente para ser de direita: (14) $\rightarrow$ (9) ou, melhor ainda, de extremadireita. Isso contradiz a nossa ideia segundo a qual não há nenhuma implicação lógica entre os conceitos políticos, reabilitando assim a relação de

\footnotetext{
${ }^{4}$ Georges Sorel (1847-1922) é considerado como o pai do sindicalismo revolucionário e o introdutor do marxismo na França enquanto inspirado por Proudhon; Ernst Niekisch (1889-1967) foi o principal influenciador da chamada 'asa esquerda' do partido nazista alemão, através dos irmães Gregor e Otto Strasser. Sobre a expressão 'nazismo de esquerda' e o seu significado ambiguo, veja (SCHANG, 2016).

${ }^{5}$ Sobre o antissemitismo de Sorel, veja em particular os historiadores Shlomo Sand: Georges Sorel en son temps (Paris, Seuil, 1985), e Zeev Sternhell (2012).
} 
analiticidade entre alguns deles. No entanto, podemos duvidar de que haja algum critério independente para justificar tal relação entre os conceitos de antissemitismo e de direita. Pelo contrário, alguns comentadores afirmaram que a atitude de Proudhon vinha da sua asimilação do judeu ao capitalismo e simbolizou por isso um 'antissemitismo de esquerda'. Aqui está presuposto tão somente um caso inverso de relação de analiticidade, em virtude do qual quem é capitalista (15) é de direita (9) e, $\log o$, por contraposição, quem é de esquerda não é capitalista ou é 'anticapitalista' (16). Mas aparecem aqui também as duas suposições análogas de que quem não é de direita é necessariamente da esquerda e que quem não é capitalista é anticapitalista, e viceversa: $(15) \leftrightarrow(9), \operatorname{logo}(8) \leftrightarrow(16)$. Retomaremos em detalhes esse ponto na próxima seção, por meio da pergunta lógica sobre se os conceitos de esquerda e direita são contraditórios ou contrários entre si. Por ora, diremos que, provavelmente, é a fim de preservar as duas relações de analiticidade (14) $\rightarrow$ (9) e (15) $\rightarrow$ (9) que Sternhell (2012) caracterizou o proto-fascismo de Sorel como sendo 'nem de direita nem de esquerda', enquanto manteve a alcunha tradicional de 'fascismo' como ideologia de 'extrema-direita'. Como alguém pode ser de 'extrema-direita' - sendo assim da categoria geral da direita, e 'nem ser de direita nem de esquerda' - não sendo assim da direita ? Ster- nhell deveria explicar tal contradição que, a menos que seja meramente retórica, não pode fazer sentido e invalida o carater análitico dos pares ordenados antissemitismo-direita e capitalismodireita. Uma alternativa pode ser a seguinte: ou bem admitimos que há anticapitalistas de direita e negar assim a relação de analiticidade entre (15) e (9): (15) $\wedge(8)$, a fim de salvar a declaração segundo a qual Sorel foi de extrema direita; ou bem abrimos o debate ao admitir que tal 'extrema direita' constitui uma expressão desajeitada para uma nova atitude política em si mesma, ou seja: 'nem direita nem esquerda'. Resta saber o que significa essa forma de 'terceira via' e o que querem os seus representantes, além de saber o que eles não querem.

Uma terceira opção, que é a que defendemos, consiste em rejeitar ambos critérios de analiticidade e de terceira via enquanto mantemos a tese de um 'conservadorismo de esquerda'. Retornando ao caso de Proudhon, podemos explicar a dificuldade em admitir esse tipo de conservadorismo da seguinte maneira: a profunda influência da noção marxista de 'ideologia da falsa consciência' (ENGELS MARX, 1993) é sem dúvida responsável pela relação de equivalência estabelecida por Marx e Engels entre as ordens econômicas e morais, isto é, a relação causal de infraestrutura a superestrutura e, consequentemente, a relação de implicação pressuposta entre o modo de pro- 
dução capitalista e o conservadorismo como vontade alienada de manter qualquer institução dominante. Aparentemente, não encontramos essa conexão em Proudhon, e o senso comum dos cientistas políticos poderia ser comparado ao resultado inconsciente da vitória do materialismo dialético de Marx sobre o socialismo utópico de Proudhon. A dificuldade em admitir a existência de uma esquerda conservadora e uma direita progressista é basicamente a mesma que admitir a existência de uma necessidade a posteriori e uma contingência a priori. A superação desse obstáculo epistemológico pressupõe, antes de tudo, uma definição mais precisa do primeiro termo, depois uma distinção entre seu significado usual e um outro significado mais particular.

Concluiremos nossa análise política com uma nota que pode ser aproximada do ceticismo epistemológico de Quine. Assim como ele desafiou a legitimidade da distinção usual entre analítico e sintético, a clara separação entre direita e esquerda repousa sobre uma oposição forçada entre a ordem econômica e a ordem moral: decidir em que casos um valor moral impõe-se a todos dentro de um determinado corpo social não é mais óbvio do que decidir quando uma afirmação é verdadeira apenas em virtude do significado de seus termos em um determinado idioma. E, assim como a clara separação entre analítico e sintético repousa na crença em um empirismo radical, reduzindo cada proposição verdadeira a um conjunto de dados observáveis, a divisão esquerda-direita repousa na crença em critérios comuns e transparentes do progresso humano. Sem dúvida, há um elemento de arbitrariedade nas distinções esquerda-direita e conservadorismo-progressismo, assim como nas oposições necessidadecontingência e a priori-a posteriori; mas isso não nos dá nenhuma razão para abandonar essas distinções, e a ideia de Bobbio de que esquerda e direita são tendências tão irredutíveis quanto difusas lembra fortemente a ideia quiniana de uma distinção de grau (e não da natureza) entre verdades lógicas e verdades empíricas.

\section{Valores lógicos, valores políticos}

- Existem chefes de esquerda, quero ensinar ao senhor.

- Também existem peixes voadores, mas que não constituem a maioria do gênero. (Michel Audiard, O Presidente)

Também costuma-se, na linguagem comum, apresentar a esquerda e a direita como valores. Será que é possível considerar essas ideias orientadoras comparáveis aos valores lógicos do verdadeiro e do falso? Não que a direita e a esquerda sejam idênticas ao verdadeiro e falso, ou vice-versa. É novamente uma reflexão analógica, sabendo que o verdadeiro e o falso são geralmente apresentados como um par de opostos. Se 
pretendemos rejeitar tal comparação, devemos antes examinar as razões teóricas para tal, antes de citar as vantagens explanatórias.

Perguntemo-nos primeiro sobre a natureza dos valores políticos, localizados em algum lugar entre valores lógicos e predicados proposicionais. Os motivos para não manter a esquerda e a direita como valores podem ser os seguintes:

- argumento minimalista: a afirmação 'Paris é a capital da França' é verdadeira ou falsa porque $\mathrm{Pa}$ ris é a capital da França ou não, ao passo que um partido político está 'à esquerda' ou 'à direita' porque ele promove tal ou tal ideologia. Deste modo, podemos explicar por que esse ou aquele partido é de esquerda ou de direita, enquanto a explicação da verdade da afirmação de que Paris é a capital da França é redundante;

- argumento axiológico: a verdade é um ideal da ciência em oposição à falsidade, enquanto esquerda e direita são dois valores que podem ser buscados separadamente e em partes iguais (mas por razões diferentes);

- argumento metalinguístico: os conceitos de verdade/falsidade e esquerda/direita não estão no mesmo nível de discurso, o primeiro sendo de ordem superior; a prova disso é que os predicados ou valores de or- dem superior 'verdadeiro' e 'falso' não aparecem na classificação dos juízos de Kant-Kripke, enquanto 'direita' e 'esquerda' aparecem na classificação das atitudes políticas.

Este último critério para distinguir entre linguagem-objeto e metalinguagem é particularmente útil para evitar paradoxos semânticos e, portanto, contra a produção de discursos antitéticos. É esse tipo de contradição que queremos testar no discurso político, de modo que se poderia perguntar: se a oposição esquerda-direita forma um par contraditório de natureza diferente do par verdadeiro-falso, por que nos parece tão absurdo pensar que um partido político pode ser de esquerda $e$ de direita ao mesmo tempo, quanto pensar que uma afirmação pode ser verdadeira e falsa ao mesmo tempo ? É certo que a suposta relação contraditória entre esquerda e direita não implica que estes sejam valores em si mesmos. Afinal, o fato de o predicado 'preto' excluir o 'branco' (e vice-versa) não significa que esses termos de cores sejam valores. Se os conceitos de esquerda e direita não são valores, o que são eles se não correspondem a nenhum objeto em particular ? A analogia com o exemplo das cores permite explicar em que medida dois termos admitem ou não um intermediário. Também explicará em que medida os conceitos de esquerda e direita estão relacionados aos valores pelo fato de eles se comportarem como expressões de atitudes morais (e não cogniti- 
vas). Explicar a lógica dessas atitudes será o último tema deste artigo.

Consideremos um agente da esquerda ou da direita como um ser moral que atribui valor a qualquer ação política (SCHANG, 2019). Uma ação é considerada boa ou ruim e isso distingue atitudes morais de atitudes cognitivas, que por sua vez se relacionam com os valores lógicos de verdade e falsidade. Essas ações podem ser interpretadas a partir de conceitos ideológicos, que são formas intermediárias de atribuir valor moral a diferentes tipos de ações entre membros de um espaço social. Mas não são apenas as ideologias numerosas e variadas: socialismo, liberalismo, nacionalismo, feminismo, humanismo, ambientalismo, etc.; além disso, essas ideologias têm definições ambíguas e suas relações lógicas são tão pouco especificadas quanto o número delas fica indeterminado. Duas questões surgem, dada essa ambiguidade.

(a) Os conceitos de esquerda e direita são definíveis como conjuntos fechados de ideologias subjacentes?

(b) Uma atitude política pode ser de esquerda e de direita ao mesmo tempo, ou nem de esquerda nem de direita?

Tentamos caracterizar a divisão esquerda-direita por analogia com os juízos kantianos e os desejos epicuristas, ou seja, a partir de uma combinação de dois conceitos principais cujos comportamentos lógicos são exclusivos e exaustivos : nenhum juízo necessário é contingente, e vice-versa ; e todo juízo é necessário ou contingente, tertium non datur. No caso da direita, nossa definição é tal que se baseia no conceito de ordem e que este último pode ser dividido em ordem econômica e ordem moral. Responder às duas perguntas acima consiste, portanto, em saber se a oposição entre esquerda e direita pode ser considerada como um conjunto de conceitos políticos que são ao mesmo tempo excludentes e exaustivos. O liberalismo é de esquerda ou de direita, por exemplo ? Se a primazia do indivíduo sobre o coletivo caracteriza o libertarianismo, ou liberalismo social, isso constitui uma atitude de progressismo que se opõe ao conceito de conservadorismo. E se a promoção de modos de troca capitalistas constitui o liberalismo econômico, então esta é uma atitude de direita, pois promove a ordem econômica estabelecida de livre comércio e se opõe à atitude esquerdista do socialismo. Portanto, alguém seria levado a pensar que a ideologia do liberalismo estaria à direita em relação à ordem econômica, enquanto estaria à esquerda em relação à ordem moral. $\mathrm{O}$ movimento 'Egalité et Réconciliation' (Igualdade e Reconciliação) de Alain Soral, por exemplo, mantém o mesmo registro quando promove um modelo político caracterizado pela 'esquerda do trabalho e direita dos valores': uma combinação nacionalista de economia 
estatal e de conservadorismo. ${ }^{6}$ Nossa análise das atitudes políticas consistiu em distinguir o conservadorismo das noções independentes de esquerda e direita : existe um conservadorismo de esquerda e um conservadorismo de direita, assim como existem juízos necessários a priori e necessários a posteriori. Em outras palavras, qualquer referência a uma atitude política simultaneamente de 'esquerda e direita' repousa ainda mais sobre uma confusão entre os dois termos combinados de direita e conservadorismo, da mesma maneira que a referência a propostas necessárias a posteriori pode dar impressão de que uma proposição seria a priori e $a$ posteriori ao mesmo tempo, desde que se pressuponha uma relação de equivalência entre necessidade e aprioridade.

Assim, se excluirmos a possibilidade de atitudes políticas de esquerda e direita, o que dizer do caso oposto de atitudes políticas que não seriam nem de esquerda nem de direita? Se nenhuma ideologia escapa à divisão exaustiva esquerda-direita, essa expressão duplamente negativa não faz mais sentido e é novamente baseada na confusão conceitual. Um exemplo de ideologia associada a essa posição incompleta é o conceito de 'terceira via', que supõe a existência de um pensamento econômico nem capitalista nem socialista.
Esta terceira via refere-se a dois tipos de correntes políticas diferentes : o populismo dos chefes de Estado (de Gaulle, Vargas, Péron, Chaves), por um lado, e a 'nova social-democracia' (Tony Blair, e seu mentor Anthony Giddens [2001]), por outro. Alain de Benoist considera o debate político atual como uma nova oposição entre populismo e elitismo, ou localismo e globalismo; ao mesmo tempo, Chantal Mouffe distingue entre populismo de esquerda e populismo de direita. Não é possível dar razão a ambos com base nas mesmas definições ; o primeiro sem dúvida interpreta o par 'esquerda-direita' como um conjunto de ideologias inactuais, enquanto a segunda concebe o populismo como um conceito ambivalente mas compatível com essa divisão tradicional.

Nossa explicação final dos casos de atitudes políticas excessivas (esquerda e direita) e incompletas (nem esquerda nem direita) será baseada em uma interpretação multivalente dos valores políticos: existiriam políticas que são de esquerda ' $e$ ' de direita no mesmo sentido em que existiriam proposições 'verdadeiras e falsas', assim como existiriam políticas que não estão 'nem' à esquerda 'nem' à direita, no mesmo sentido em que não existiriam proposições 'nem verdadeiras nem falsas'. Esses casos de valores não-clássicos podem ser

\footnotetext{
${ }^{6}$ Essa máxima resume a associação política 'Égalité \& Réconciliation' (Igualdade e Reconciliação) de Alain Soral: $<$ https://www.egaliteetreconciliation.fr>. Apesar das acusações de antissemitismo contra esse movimento, não consideramos isso como uma razão suficiente para recusar a noção correspondente de 'conservadorismo de esquerda' e validar a relação de analiticidade entre direita e conservadorismo. Fazer isso seria um caso de reductio ad hitlerum.
} 
adaptados ao princípio da bivalência, em virtude do qual qualquer proposição é verdadeira ou falsa. No primeiro caso, uma atitude política pode ser considerada como de esquerda 'e' de direita quando sendo 'não totalmente' de direita e 'não totalmente' de esquerda. A fórmula anterior de Soral é desse tipo, e mostramos como ela se baseia na confusão conceitual entre direita e conservadorismo. Outra maneira de entender a atitude política contraditória é assimilá-la ao conceito metapolítico de centro. O próprio Bobbio abordou a questão (b) acima através da noção de centro, aludindo ao princípio lógico do terceiro excluído. O problema foi reformulado por ele nos seguintes termos: o espectro político obedece à lei do terceiro excluído, à lei do terceiro incluído, ou à lei do terceiro inclusivo? Segundo a primeira lei, qualquer atitude política é de esquerda ou de direita, tertium non datur. Pela a segunda lei, uma atitude política pode ser dita nem de esquerda nem de de direita quando é de centro. E de acordo com a terceira lei, uma atitude política pode ser de direita e também de esquerda. Bobbio promoveu a primeira posição, reduzindo o centro a uma tendência variável de esquerda ou de direita e o acompanharemos neste ponto : centro-esquerda e centro-direita constituiriam atitudes de 'moderantismo' que não aplicam os mesmos tipos de juízo moral em todos os casos, em contraste com as atitudes categóricas da extrema-direita e da extrema esquerda. Deve-se observar que esta interpretação do centro concorda com a definição da necessidade de Kripke em termos de verdade em 'todos' os mundos possíveis, constituindo um tipo de contingência política em virtude da qual uma atitude política seria boa ou apropriada em determinadas situações (mas não em todas). A 'socialdemocracia' de centro-esquerda insistiria mais no progressismo enquanto fosse compativel com a ordem econômica estabelecida; o 'social-liberalismo' de centro-direita privilegiaria o livre comércio econômico enquanto admitir uma certa dose de progressismo. Essas duas atitudes são nada mais do que formulações alternativas da direita econômica combinada com o progressivismo, a centro-esquerda preferindo o nome de 'progressismo' ao de 'direita' e a centrodireita exibindo uma postura oposta. Mas os efeitos práticos são os mesmos e as duas atitudes produzem as mesmas ações públicas, da mesma maneira que um juízo contingente a priori significa a mesma coisa que um juízo $a$ priori contingente. A diferença entre as duas atitudes é uma simples questão de aparência pública : insistir em um dos dois termos é esconder o que provavelmente desagradará a base eleitoral esperada. Também podemos insistir no aspecto contingente de um juízo ou no seu modo de conhecimento a priori, o que não o torna, contudo, menos contingente ou a priori. 


\section{Holismo político}

Ser de esquerda é, como ser de direita, uma das infinitas maneiras que o homem pode escolher para ser um imbecil: ambas, com efeito, são formas de hemiplegia moral.

(José Ortega y Gasset, A rebelião das massas)

Há uma diferença entre palavras e coisas, e a divisão esquerda-direita não poderia ser mais representativa dessa ambivalência entre o que as coisas são e o que as pessoas dizem sobre elas. Portanto, vamos nos colocar agora duas questões relacionadas à identidade dos entes políticos e à lógica do discurso político.

(I) O que significa 'ser' de esquerda ou de direita?

Nossa resposta é que esquerda e direita se referem a dois tipos de comportamento político global, ou seja, duas maneiras opostas de conceber um modelo de harmonia social dentro de um determinado espaço público e em virtude de critérios de ação que são as ideologias. Mas ser algo politicamente não é apenas falar como tal, é também agir de um modo esperado. A distinção inicial entre pensar e fazer pode ajudar nesse ponto : existem homens à direita que, no entanto, estão considerados de esquerda (e vice-versa), quando seus próprios pensamentos ou sensibilidades políticas não coincidem com seu compromisso público. François Mitterrand, embora fosse um homem $\grave{a}$ esquerda, era um homem de direita, ao passo que Jacques Chirac, que era um homem à direita, foi um homem de esquerda. $^{7}$

(II) Quais são as condições necessárias e suficientes para ser de esquerda ou de direita?

As modalidades desse espaço e os critérios de ação são tão variados e confusos que a definição da divisão esquerdadireita é suficiente para desencorajar qualquer um. No entanto, isso não implica a inutilidade ou insignificância dessa divisão, assim como as dúvidas de Quine sobre o significado da divisão analítico-sintético não implicam a insignificância desses dois conceitos antitéticos herdados de Kant. Em vez disso, digamos que esquerda e direita são conceitos operacionais, ou seja, hipóteses 'convenientes' (para falar como Henri Poincaré), cujo significado depende tanto da ação prática quanto do discurso teórico. Em outras palavras, esses dois conceitos metapolíticos tornam possível dar um significado ou uma orientação geral a uma ação polí-

\footnotetext{
${ }^{7}$ François Mitterrand (1916-1996) foi o primeiro Presidente da República Francesa (de 1981 a 1995) do Partido Socialista (PS), portanto classificado de 'esquerda'. Jacques Chirac (1932-2019) foi o sucessor de Mitterrand na chefia do Estado francês (1995-2007), após ter fundado o partido gaullista do Rally pela República (RPR) em 1976.
} 
tica; mas qualificar uma dada ação política como 'de esquerda' ou 'de direita' continua sendo um exercício perigoso, por causa desse aspecto convencional (e, portanto, inobservável) dos dois termos opostos.

Nossa resposta a (II), quanto a isso, vem ao encontro da posição de Quine em relação à distinção analíticosintético: não sabemos exatamente como definir a esquerda e a direita, pois a definição desses dois conceitos sempre depende de termos ambíguos. Isso não significa, no entanto, que a divisão esquerda-direita não faça sentido, mas que a distinção entre as duas é gradual e pode ser comparada àquela entre duas cores: 'sabemos' distinguir o verde do vermelho, mesmo se somos completamente incapazes de dar uma definição precisa dessas cores; e também sabemos que um objeto não é vermelho se for verde, e vice-versa. A reflexão de Goodman (1955) sobre o processo de indução é interessante a esse respeito: poderíamos considerar o uso de nomes de cores como 'verzul' (ou 'azerde'), para nos referir a esmeraldas que seriam as primeiras verde (ou azul) antes de se tornar azul (ou verde) após um certo tempo; no entanto, não usamos esses neologismos e continuamos a usar nomes de cores categóricos. O mesmo acontece na esfera política, onde 'desquerda' e 'ereita' são apenas fórmulas sarcásticas.

O resultado dessa reflexão é uma espécie de holismo semântico adaptado ao domínio político: o significado de uma atitude política depende do conjunto de atitudes consideradas em um modelo historicamente determinado, e a posição da esquerda e da direita depende da interação entre as várias ideologias que compõem o pensamento político nesse modelo. Isso significa que os conceitos de esquerda e direita não podem ser definidos com base em uma atitude singular ou em uma definição geral.

Por fim, a natureza gradual da clivagem esquerda-direita pode ser comparada aos famosos paradoxos sorites: não sabemos quanto dos cabelos arrancados deixam uma pessoa careca, ou quantos grãos de areia são necessários e suficientes para produzir um monte. Mas sabemos o que significa calvície e o que significa um monte. Da mesma forma, pode-se perguntar quando uma política fica de esquerda (ou de direita) depois de estar de direita (ou de esquerda). O caso da 'terceira via', ou 'nova social-democracia', segue esse registro ao constituir uma espécie de direitização da social-democracia, esta já constituíndo uma direitização do socialismo. Não sabemos quando tal uma 'direita da direita' do socialismo cruza a fronteira da esquerda para se tornar uma política da direita, pela simples razão de que essa fronteira é apenas teórica e manifesta o caráter convencional da divisão esquerda-direita. 


\section{Conclusão: A clareza na confusão}

Hoje, o vencedor não é o homem forte e inteligente, mas o pequenino, o espertinho, aquele que sabe lidar com chantagens com uma [veja se é isso mesmo] Winchester. E acima de tudo a confusão na clareza.

(Claude Lelouch, $A$ aventura é uma aventura)

Propusemos uma definição dessa divisão entre esquerda e direita, mas sem afirmar que sua aplicação prática esclarece todo o cenário político atual. Resta fazer uma análise formal dessa paisagem e das relações inferenciais entre as várias atitudes que as compõem. A lógica dessas relações vinculando com atitudes morais, ela não pode ser explicada em termos de valores de verdade e deve ser capaz de dizer o que um agente político deve e não deve fazer de acordo com os seus próprios compromissos ideológicos. Uma lógica de imperativos deve ajudar alguma coisa [é isso mesmo?] a este respeito [24].

Também refutamos a possibilidade de atitudes políticas 'nem de esquerda nem de direita', reinterpretando o centrismo como um tipo de atitude moderada ou relacionada a contextos de ação. O mesmo se aplica às possibilidades de ações de esquerda 'e' de di- reita, reduzindo essa fórmula contraditória a um exemplo de confusão conceitual. O exemplo do movimento dos coletes amarelos na França é instrutivo neste ponto, porque lembra um tipo completamente diferente de lógica: a lógica transcendental de Kant, que especifica as condições de possibilidade da experiência com base em uma síntese das intuições puras (espaço e tempo) e das categorias puras do entendimento. Em contraste com a 'lógica' hegeliana, onde tudo parece contraditório, acreditamos que as duas formas de discurso político incompleto (nem esquerda nem direita) e excedente (esquerda e direita ao mesmo tempo) são apenas os dois lados da mesma moeda: aquelas em que nada pode ser feito em particular porque tudo pode ser dito em geral, resultante de uma confusão conceitual voluntária que impede a clareza do discurso político, cria uma impressão geral de niilismo semântico [19] e garante a manutenção de profissionais políticos no poder, na ausência de uma alternativa concebível (através de programas claros e objetivos).

Esta atitude de cinismo político pode ser descrita como um extremo centro. ${ }^{8}$ Tal expressão pode parecer tão paradoxal quanto aquela 'necessidade contingente', na medida em que tudo o que é

\footnotetext{
${ }^{8}$ Sobre as origens históricas desse conceito, veja a entrada correspondente do site Wikipédia (em francês): <https://fr.wikipedia.org/wiki/Extrême_centre\# cite_ref-Deneault2016_5-0, bem como um análise do fenomeno contemporenao pelo filosofo canadense Alain Denault (2017). Embora a aparência oximorônica desse apelido pode levar a algumas críticas, consideramos pelo contrario que ele ajuda abrir nossas perspectivas de reflexão em ciência política ao considerar o 'extremo' como uma postura que também se aplica ao centro.
} 
necessário não pode ser contingente (e vice-versa). No entanto, o extremo centro corresponde a uma espécie de contingência necessária que não é nem uma mera contingência nem uma mera necessidade: de acordo com as nossas interpretações anteriores do extremismo (a mesma atitude em todos os contextos) e centrismo (as atitudes dependem do contexto, então uma atitude aparece em alguns contextos mas não em todos), o 'extremo-centro' corresponde a uma atitude em que é sempre o contexto que determina a atitude do agente político. Em outras palavras, nenhuma atitude é a mesma no extremo-centristo pois as convicções ideológicas não existem neste tipo de agente político. Certamente não é esse o significado do slogan 'nem esquerda nem direita' dos coletes amarelos, cuja principal aspiração é o retorno às condições normais de exercício da soberania política.

A divisão esquerda-direita faz sentido em todos os lugares e sempre, portanto, mas com a condição de que sejam dados os meios para se manifestar na forma de ações políticas que emanam da vontade do povo. Quine poderia nos lembrar, assim, da ambiguidade do conceito primordial de povo por meio da divisa: 'Nenhuma entidade sem identidade'. Qualquer que seja a identidade de povo, privar o cidadão de seu poder soberano, eliminando a divisão esquerda-direita, equivale a privar o sujeito de seu poder de julgar e, deste modo, o priva de seu status de soberano político, agente moral e sujeito pensante. Quine, Kant e Epicuro certamente nos concederiam isso.

\section{Referências}

BOBBIO, N. Direita e esquerda. Razões e significados de uma distinção política. Ed. UNESP, 1994.

CLOUSCARD, M. Néo-fascisme et idéologie du désir: Mai 1968, la contre-révolution libérale. Ed. Broché, 2008.

DE BENOIST, A. Droite-gauche c'est fini! Le moment populiste, Ed. Broché, 2017.

DENAULT, A. Politiques de l'extrême centre. Éditions Lux, collection Lettres Libres, 2017.

ENGELS, F. MARX, K. A ideologia alemã, 1845-1846. Tradução de José Carlos Bruni e Marco Aurélio Nogueira, 9a edição, ed. Ciências Humanas, São Paulo, 1993.

GIDDENS, A. A Terceira Via e seus Críticos. Rio de Janeiro, Record, 2001.

GOODMAN, N. Fact, Fiction and Forecast. Cambridge, MA: Harvard UP, 1955

HINTIKKA, J. "Epistemic logic and the methods of philosophical analysis", Australasian of Philosophy, Vol. 46, 1968, pp. 37-51.

ISABEL, T. Pierre-Joseph Proudhon. L'anarchie sans le désordre. Ed. Autrement, 2017.

JULLIARD, J. Les gauches françaises (1762-2012). Histoire, politique et imaginaire. Ed. Broché 2012.

KANT, I. Crítica da razão pura. Ed. Vozes, 2015.

KRIPKE, S. O nomear e a necessidade. Ed. Gradiva, 2012.

LOTY, L. "Islamisme, laïcité féministe et ultra-libéralisme". In: La modernité discutée (Textes offerts à Pierre-André Taguieff), CNRS Editions, 2019, pp. 391-402.

MOUFFE, C. Pour un populisme de gauche. Ed. Broché, 2018.

QUINE, W.V.O. “Os dois dogmas do empirismo”. In: Ryle et al. Coleção Os Pensadores: Vol. LII. São Paulo: Abril Cultural, 1975, pp. 237-254.

QUINE, W.V.O. Philosophy of Logic. Harvard Univ. Press (2a ed.), 1986.

RÉMOND, R. Les droites en France. Ed. Aubier- Montaigne, Paris, 1954. 
SALANSKIS, J.-M. La gauche et l'égalité, Collection Intervention philosophique, 2009.

SCHANG, F. "Non-Epicurean desires", Unisinos Journal of Philosophy, 17(1), 2016, pp. 63-68.

SCHANG, F. "Le ninisme est-il un nihilisme?", Implications Philosophiques, 2015, <http ://www.implications-philosophiques.org/actualite/une/le-ninisme-est-il-un-nihilisme/>.Acesso em: 20 mar. 2020.

SCHANG, F. "Politicamente falando: Um ensaio em filosofia da linguagem politica" (Manuscrito).

SCHANG, F. "Uma análise operacional da distinção esquerda-direita". In: Anais do 1o Fórum de Ciência Politica da Universidade Federal de Goiás, 2019, pp. 135-155

STERNHELL, Z. Ni droite ni gauche, l'idéologie fasciste en France, Folio Histoire, 2012.

VRANAS, P. "Logic of Imperatives". In: The International Encyclopedia of Ethics, Hugh LaFollette (ed.), 2015, pp. 1-10.

Recebido: $01 / 01 / 2020$

Aprovado: $13 / 04 / 2020$

Publicado: $30 / 12 / 2020$ 
